\title{
De algunas influencias alemanas en Colombia y su exhortación actual al psicólogo
}

\author{
John Alejandro Ramírez Tobón*
}

\begin{abstract}
Resumen
Alemania es un referente mundial en muchos ámbitos del conocimiento humano, especialmente el científico y el humanístico. En este ensayo se tratará de explicar cómo Alemania, finalizando el siglo xix y hasta la década de los sesenta del siglo xx, influyó en Colombia en tres campos humanísticos: la filosofía, la psicología y la pedagogía, tres disciplinas estrechamente relacionadas que se sirvieron de los conocimientos y avances alemanes representados en figuras eminentes como Nietzsche, Heidegger, Wundt y Franziska Radke. Se relacionará la influencia de cada uno a la disciplina específica. Al finalizar el ensayo, se retomará el aporte de Nietzsche y Heidegger, que se constituye así en el argumento central de este escrito que explica la vigencia de ambos planteamientos en la realidad actual colombiana afirmando la "encarnación" del olvido del ser planteado por Heidegger y la reivindicación de lo humano planteada por Nietzsche. Por otro lado, se invita a la psicología, desde el pensamiento de ambos filósofos, a plantear desde su quehacer investigativo o de intervención, alternativas que propendan por ese "volver al ser" interpretado en este texto como "volver a lo humano". En este sentido, el papel del psicólogo se reivindica en un contexto deshumanizante como el que ha generado el conflicto colombiano.
\end{abstract}

Palabras clave: Alemania, Colombia, filosofía, pedagogía, psicología, retorno a lo humano.

\section{German Influences in Colombia and their Current Exhortation to Psychologists}

\section{Abstract}

Germany represents a worldwide reference in many fields of human knowledge, especially in science and the humanities. This essay attempts to explain how Germany, from the end of the 19th century to the 1970s, influenced Colombia in three fields of humanities: philosophy, psychology and pedagogy. These three closely related disciplines were enriched by German knowledge and the advances of such prominent figures as Nietzsche, Heidegger, Wundt and Franziska Radke. This article relates the influence of each of these figures to a specific discipline. At the end of the essay, the contributions of Nietzsche and Heidegger are revisited and thus become the central argument of this piece in explaining the continued validity of both approaches in current-day Colombia. Thus the "incarnation" of the forgetting of being proposed by Heidegger, and the reclaiming of the human put forward by Nietzsche are affirmed. Furthermore, an invitation is extended to psychology, based on the thinking of both philosophers, to propose alternatives from its research practice or intervention that promote this "return to being", interpreted in this text as a "return to the human". In this sense, the role of the psychologist is reaffirmed in a dehumanizing context such as that created by the Colombian conflict.

Keywords: Germany, Colombia, philosophy, pedagogy, psychology, a return to the human.

\section{De algumas influências alemãs na Colômbia e sua exortação atual ao psicólogo}

\section{Resumo}

A Alemanha é um referente mundial em muitos âmbitos do conhecimento humano, especialmente o científico e o humanístico. Neste ensaio se pretende explicar como a Alemanha, ao finalizar o século XIX e até a década dos 1960, influenciou a Colômbia em três campos humanísticos: filosofia, psicologia e pedagogia; três disciplinas estreitamente relacionadas que se serviram dos conhecimentos e avanços alemães representados em figuras eminentes como Nietzsche, Heidegger, Wundt e Franziska Radke. Será relacionada a influência de cada um na disciplina específica. Ao finalizar o ensaio, será retomada a contribuição de Nietzsche e Heidegger, que se constitui assim no argumento central deste texto, o qual explica a vigência de ambas as proposições na realidade atual colombiana ao afirmar a "encarnação" do esquecimento do ser proposto por Heidegger e a reivindicação do humano proposta por Nietzsche. Por outro lado, faz-se um convite à psicologia, a partir do pensamento de ambos os filósofos, a propor a partir do seu fazer investigativo ou de intervenção, alternativas que propendam por esse "voltar a ser" interpretado neste texto como "voltar ao humano". Nesse sentido, o papel do psicólogo se reivindica num contexto desumanizador como o que tem gerado o conflito colombiano.

Palavras-chave: Alemanha, Colômbia, filosofia, pedagogia, psicologia, retorno ao humano.
Cómo citar este artículo: Ramírez, J. A. (2014). De algunas influencias alemanas en Colombia y su exhortación actual al psicólogo. Pensando Psicología, 10(17), 149-154. doi: http://dx.doi.org/10.16925/pe.v10i17.893 


\section{Un poco de historia y algunas influencias alemanas ${ }^{1}$}

Las corrientes del pensamiento unen constantemente a Colombia y Alemania, dos naciones esencialmente distintas al mismo tiempo que similares. Distintas en su evolución histórico-cultural y en su construcción de mundo y de hombre, pero similares dado que conformadas por seres humanos, estos comparten esencialmente las mismas esperanzas y temores vitales, comunes a las personas independientemente de su cultura, religión, raza, ubicación geográfica, política, condición social o económica. Similares también en un tópico central y neurálgico para ambas naciones en momentos precisos y definitivos de su historia: la guerra, que, aunque con orígenes y consecuencias distintas, ambas naciones han experimentado en su salvajismo y sus consecuencias.

Es decir, tanto el ser humano colombiano como el alemán, aunque distintos incluso en su aspecto físico y en su manera de relacionarse con el mundo, experimentan las mismas emociones que fluctúan de la esperanza al miedo, y entre ellas dos todos los matices posibles. Por otro lado, se han encontrado de frente con la guerra. En este sentido, somos diferentes pero somos similares, tenemos un mismo nombre (seres humanos) con apellidos diferentes.

La historia legitima cómo Alemania desde su contexto occidental y su propia construcción de cultura caracterizada por un alto nivel, manifestada especialmente en las letras (Goethe, Grass), la música (Bach, Beethoven) y la ciencia (Kepler, Einstein, Plank), ha servido de influencia constante no sólo a Colombia, sino al mundo entero, marcando muchas veces las rutas a seguir en diversos ámbitos del saber humano. Especialmente desde finales del siglo XIX hasta pasada la primera mitad del siglo xx, existe en la historia de Colombia una importante influencia alemana, específicamente en el campo humanístico, periodo en el que sirvió de inspiración para la pedagogía, la filosofía y la psicología colombianas. Esta influencia se enmarca en las teorías de grandes pensadores alemanes, quienes fueron referenciados, bien para la fundamentación de la disciplina, en el caso de la psicología, o bien para su desarrollo y enriquecimiento como en el caso de la filosofía y la pedagogía.

\footnotetext{
1 Ensayo ganador del Primer Concurso Nacional de Ensayos organizado por el Fondo Editorial de la Universidad Cooperativa de Colombia, dentro del marco de la Semana Internacional Global Festival Alemania, en la Universidad Cooperativa de Colombia, 2013.
}

En el campo de la filosofía, Nietzsche, como representante del "Vitalismo", y Heidegger como uno de los representantes del existencialismo alemán, inspiraron a muchos de los pensadores colombianos, quienes desde la interpretación realizada a estos filósofos fundaron corrientes vanguardistas, atreviéndose a pensar diferente, cuestionando los paradigmas operantes de la época. En particular el Nadaísmo, precisamente como propuesta filosófico-literaria, promulgó el declive de un orden preestablecido, socioculturalmente hablando, una crítica directa a la tradición y la normalidad social y en constante contradicción con los sistemas operantes en la época, especialmente el religioso y el político (Acevedo y Restrepo, 2009). El Nadaísmo retoma lo planteado por el Nihilismo, expresión emparentada con el Nadaísmo (RodríguezPouget, 2008), presente en Nietzsche y en Heidegger, con matices similares pero diferentes en cada uno de ellos. Nietzsche lo relacionaba con la "muerte de Dios" (Nietzsche, 2010), condición necesaria para que nazca el "superhombre" (Übermensch) capaz de crear su propio sistema de valores radicalmente opuesto al impuesto por el cristianismo (Nietzsche, 1982), y Heidegger lo relaciona con el abandono del ser, considerando el Nihilismo como la esencia misma de ese abandono al que se ha sometido al ser en occidente (Rivero y Rivara, 2002). Subyace en el Nadaísmo, inspirado en la acepción nihilista, un deseo profundo de reivindicación y recuperación de lo humano, de volver al ser, preocupación manifiesta tanto en Nietzsche como en Heidegger. Es así que autores como Gonzalo Arango (discípulo del filósofo Fernando González), Jotamario Arbeláez, Amílcar Osorio, Eduardo Escobar y Alberto Escobar Ángel, crean el movimiento, considerado incluso como extensión latinoamericana del Existencialismo (Rodríguez-Pouget, 2008), retomando algunos planteamientos de Sartre y Nietzsche, así como otras influencias:

Los movimientos artísticos, literarios y filosóficos que ejercieron mayor influencia en los nadaístas fueron el futurismo ruso, el surrealismo, la patafísica de Alfred Jarry, la generación Beat y el existencialismo, particularmente en las figuras de Jean Paul Sartre y Friedrich Nietzsche (Carrillo, 2006).

Propendió por la reivindicación de lo humano, fundamentándose en la rebeldía, los principios anárquicos y el rechazo mordaz y frontal a una sociedad consumista: 
El nadaísmo es un estado del espíritu revolucionario, y excede toda clase de previsiones y posibilidades. Para la juventud es un estado esquizofrénico-consciente contra los estados pasivos del espíritu y la cultura... Para nosotros este es el mundo y este es el hombre, la libertad es, en síntesis, un acto que se compromete. No es un sentimiento, ni una idea, ni una pasión. Es un acto vertido en el mundo de la historia (Arango, 1958).

Vemos entonces cómo el movimiento nadaísta está emparentado con el pensamiento nietzscheano y heideggeriano fundamentalmente en lo relacionado con el nihilismo propuesto por ambos, inicialmente por Nietzsche y seguidamente avalado por Heidegger (Rivero y Rivara, 2002), adquiriendo matices regionales en contra de los sistemas político, económico y religioso de la época, haciendo un llamado al despertar de la ignorancia y la masificación del pueblo colombiano. Subyace en su ideología un "mirar lo humano", alejada de todo aparato que lo aliene.

Con respecto a la pedagogía, es clave anotar los esfuerzos del gobierno colombiano iniciando el siglo xx por mejorar la educación nacional, creando las denominadas "misiones pedagógicas", lideradas por especialistas alemanes. En la segunda misión pedagógica, la alemana Franziska Radke tuvo un papel fundamental siendo pionera en la fundación del Instituto Pedagógico Nacional de Señoritas en 1927, que permitió la incursión protagónica de la mujer en la educación colombiana (Helg, 1987); seguidamente; el 20 de septiembre de 1929, por medio del Decreto N. ${ }^{\circ} 1575$ se reglamentó la educación secundaria para mujeres (Angulo, 2007), gracias, entre otras cosas, al constante esfuerzo de Radke. Siete años más tarde, el Instituto Pedagógico Nacional para Señoritas solicita la creación de la Facultad de Ciencias de la Educación para Mujeres, solicitud aprobada anexando dicha Facultad a la Universidad Nacional (Ocampo, 1998). Según Angulo (2007), "finalizando su dirección del Instituto Pedagógico en 1936, Radke lo entregó con las siguientes instalaciones: El Instituto Pedagógico Nacional, la Escuela Anexa, la Casa de la Maestra, la Casa del Jardín Infantil, la Casa-quinta". Estos hechos dan cuenta de la vital importancia del trabajo realizado por Radke, incentivando el papel de la mujer en la transformación y el desarrollo de la educación nacional y aportando la innovación curricular al ámbito educativo nacional. En general, las misiones alemanas instauraron la preocupación por una educación de calidad acorde con estándares internacionales, promovieron la ampliación de la cobertura educativa, dejaron en claro la necesidad de formar adecuadamente a los docentes y de generar mejores condiciones para la educación en Colombia.

En el campo de la psicología, cabe anotar el auge de la psicología experimental fundada por el médico Wilhelm Maximiliam Wundt en Leipzig, Alemania, además de los estudios realizados en la misma ciudad, enfocados en el campo fisiológico de otros médicos investigadores como Heinrich Weber y Gustav Theodor Fechner, a finales del siglo xIx (Sprung y Sprung, 1983). Indiscutiblemente, el detonante de este fenómeno fue la instauración por primera vez de un laboratorio en 1879 por Wundt y sus colaboradores Max Friedrich y Stanley Hall (Gutiérrez, 2003). Estas ideas de una psicología científica muy pronto recorrieron el mundo, y Colombia no fue la excepción, pues, a escasos años del surgimiento de la psicología experimental, diferentes tesis médicas prosperaron teniendo como tema fundamental la relación fisiología-psicología, haciendo propias las teorías nacidas en Leipzig y, de paso, biologizando el estudio psicológico en aras de ofrecerle un carácter científico (Peña, 1993). La psicología en el país apenas daba sus primeros pasos como disciplina $y$ es el auge experimental fundamentado en el conocimiento científico, que da un impulso cardinal a los investigadores interesados por reorientar el curso de la naciente disciplina.

Relacionamos así algunas influencias importantes de Alemania sobre Colombia entre finales del siglo XIX y pasada la mitad del siglo $\mathrm{Xx}$, en tres disciplinas humanistas, representadas por grandes figuras como Heidegger, Nietzsche y Wundt y de un personaje vital para la historia de la educación en Colombia: Franziska Radke. En este ensayo, se profundizará en los aportes de Nietzsche y Heidegger desde su filosofía, las implicaciones que puedan tener en nuestra realidad colombiana y la exhortación tácita que hacen a la figura del psicólogo. El sentido y angustioso llamado de ambos a la reivindicación de lo humano, cada uno desde su matiz diferente, Heidegger desde su preocupación por recuperar el ser en su sentido puro, y Nietzsche desde su preocupación por la reafirmación y defensa de la vida, ambos pensadores vivieron en una época tan distinta a la nuestra, al mismo tiempo que similar, revestida hoy por la enajenación del ser, la alienación, el abandono de lo esencialmente humano, la globalización y con ella la despersonalización, la superficialidad, el consumismo incluso del mismo ser humano, la ciencia por la ciencia muchas veces desligada de la bioética. 


\section{Del olvido del ser, una sentencia encarnada en Colombia y la reivindicación de lo humano desde la perspectiva nietzscheana}

Colombia parece encarnar las palabras del filósofo alemán Heidegger (1999), quien afirma el olvido del ser en el que se ve inmerso occidente, pensamiento expresado en un tiempo diferente al actual, que obedecía a una realidad específica enmarcada en el cambio de paradigma racionalista a un paradigma más existencialista, que criticó la razón como única herramienta adecuada para acceder a la verdad, generando un giro vital capaz de observar al hombre en su conjunto sin verlo desprovisto de su corporeidad, mucho menos escindido de ella, situado en el mundo y responsable de su historia.

Al mismo tiempo, la realidad histórica por la que atravesaba Europa daba cuenta del cada vez más imperante positivismo, nacido hacia inicios del siglo XIX basado en los planteamientos de Comte, Saint-Simon y Stuart Mill, y su apología del conocimiento positivo basado en el método científico como único verdadero, posible y demostrable, paradigma que marcará la forma de ver y entender el mundo moderno. Comte, por ejemplo, afirmaba que es sólo en el estadio positivo, y no en el teológico o el metafísico, en el que el hombre logra, guiado por la razón y la demostración, conocimientos certeros (Antiseri y Reale, 1999), es así como la ciencia se presenta como el nuevo paradigma del conocimiento capaz de describir los fenómenos observables $\mathrm{y}$ verificarlos, acercando al hombre al conocimiento de las cosas (Jiménez, 2008).

Filósofos como Vattimo, Foucault y Gadamer comprenderán esa realidad positivista y la refutarán. Vattimo, por su parte, desde la propuesta de su "pensiero debole" niega la rigidez positivista y toda aquella manifestación univocista y monolítica que pretende afirmar una única manera de acercarse a la realidad (Vattimo, 1994). Gadamer se niega a aceptar una única manera de interpretación de la realidad (Gadamer, 1993); este mismo filósofo, testigo de dos guerras mundiales, critica fuertemente la "pretensión humana de dominar la naturaleza y sustituirla con objetos tecnologizados, situación que provoca un proceso de aniquilación del propio hombre" (García-Perea, 1999). Foucault nos ilumina en este aspecto, al dudar del discurso científico:

Es ahí donde una cultura, librándose insensiblemente de los órdenes empíricos que le prescriben sus códigos primarios, instaura una primera distancia con relación a ellos, les hace perder su transparencia inicial, cesa de dejarse atravesar pasivamente por ellos, se desprende de sus poderes inmediatos e invisibles, se libera lo suficiente para darse cuenta de que estos órdenes no son los únicos posibles ni los mejores (Foucault, 1968).

Paralelo a ello, y determinada por el positivismo, se desarrolla la Revolución industrial y, con ella, todos los cambios económicos, sociales, demográficos y culturales que trae, contribuyendo así a la consolidación de una nueva concepción de hombre supeditado a la máquina, la industria, la producción, las extensas jornadas laborales y el descuido paulatino de su humanidad. Sin duda alguna, este contexto exhorta a Heidegger y a Nietzsche e impregna su filosofía basada; para el primero, en una refutación profunda a todas esas realidades alienadoras que daban cuenta del olvido sistemático del ser, de ese vacío ontológico al que se ve sometido occidente, y para el segundo, en esa enajenación de lo humano, sometido a valores absolutos tan ajenos al propio hombre y su existencia.

Fundamentalmente, existe una realidad que tiene un matiz especial que se constituye en punto de encuentro entre Colombia y Alemania: la guerra. Ella expuso una crisis de los valores occidentales, sembró el caos, el desasosiego y la angustia, sacó a relucir la miseria humana en el más estricto sentido literal de la palabra. Es en Colombia en donde de especial manera se viven experiencias que se alejan de ser racionales, sometiendo la dignidad del ser humano a sus más crueles expresiones. $Y$ es que ciertamente el sentido del ser, visto como "ser humano", ser ahí “Dasein" (Muñoz, 2007), Heidegger incluso renuncia de manera inflexible al empleo de la nomenclatura hombre y, en su lugar, habla de dasein (Santiesteban, 2005), es desvirtuado, degenerado, desprovisto de su esencialidad, en la realidad colombiana. Se hace necesario retomar ese camino original de respeto al ser, entendido desde su integralidad como realidad digna de respeto. Ese retorno al ser podemos interpretarlo como el retorno a lo humano, titánica tarea en la cual es imprescindible la labor de la psicología, pues gracias a ella (y está apoyada en otras disciplinas como la filosofía), podemos responder preguntas tan esenciales para el hombre como ¿quién soy?, ¿qué sentido tiene mi existencia?, ¿cómo me encuentro actualmente?, ¿cómo relacionarme con los demás?, ¿qué debo aceptar en mí? o ¿qué debo comprender en mí y en los demás?

Paradójicamente, inmersos en una cultura globalizada regulada por las tecnologías de la comunicación y la 
información que nos hacen testigos de los avances científicos jamás pensados, capaces de hacerle más fácil y placentera la vida a las personas, "el sentido de lo humano" (Maturana, 2002) se va diluyendo vertiginosamente y ante la vista atónica e impávida de los mismos seres humanos quienes nos dejamos alienar consciente o inconscientemente por la máquina aplastante de la cultura contemporánea y sus paradigmas pragmáticos, cientificistas y deshumanizantes. Los colombianos debemos sumarle a las anteriores realidades las que tenemos que enfrentar a diario: microtráfico, narcotráfico, guerrilla, secuestro, violencia, corrupción, fruto de nuestra particular manera de construir la historia, que parece acostumbrarse a una cultura en contra de lo humano. Es en este sentido que se hace necesario encarnar las ideas y los planteamientos de personas como Heidegger y Nietzsche con un sentido honesto del hombre, que han planteado alternativas racionales para enfrentar la existencia. Su invitación es simple pero profunda y radical: volvamos al ser, apostemos por la vida del hombre.

¿Cuál es el papel de la psicología en este contexto? ¿Qué debe hacer el psicólogo? Indudablemente, debe hacer algo y no precisamente desde el papel pasivo de observador, sino desde una posición activa, crítica y humanizadora. Ese "algo" referido a unas acciones determinadas desde su quehacer psicológico bien sea desde el campo investigativo o desde la intervención en los diferentes campos de la psicología que ataquen frontalmente el hipnotismo en el que nos sumerge la guerra. En un país mórbido, que carece de amor, sumido en el odio entre hermanos y los vicios sociales creados a partir de las particulares realidades que se generan en Colombia, se hace necesaria la palabra del psicólogo, una palabra que, en términos de Humberto Maturana, reivindique el amor como emoción fundamental constitutiva de lo humano: "comprender esto es algo absolutamente esencial para comprender lo humano, porque en nuestro proceso de desarrollo individual como seres humanos, el amor es un elemento fundamental desde el útero hasta la tumba" (Maturana, 2002). El psicólogo moviliza conciencias desde su palabra. Colombia no necesita un psicólogo que se preste para perpetuar las realidades opresoras, alienantes y destructivas de la sociedad actual, menos un psicólogo borrego, títere de sistemas políticos, religiosos o económicos que fallando a su ética renuncia a sus principios por diluirse en ideologías desvirtuadoras de lo humano; tampoco un psicólogo cuyos esfuerzos estén encaminados única y exclusivamente a escudriñar en la persona eso negativo, eso trastornado, eso patológico, rotulándola así, haciéndole cargar a cuestas un peso más que la estigmatiza y casi que la condena a llevar indefinidamente. Colombia necesita un psicólogo consciente de que, antes de ser psicólogo, es un ser humano capaz de sentir $\mathrm{y}$ de comprender. No es una simple figura que se enajena frente a su "cliente" simulándose como no humano, insensible, no emotivo. Es por el contrario un ser que se comprende y, por tanto, es capaz de comprender al otro, un ser que se emociona y, por tanto, es capaz de entender la emoción del otro, pero que también siente con la emoción del otro. Colombia necesita profesionales que la ayuden a reencontrar su ser y le recuerden la importancia de volver a lo humano, que comprendan los fenómenos operantes de la realidad y de una manera decidida los enfrenten apoyados en sus conocimientos y su vocación a favor de la potenciación de lo humano.

\section{Referencias}

Acevedo, Á. y Restrepo, R. (2009). Una lanza por un proyecto de nación: Nadaísmo 70. Revista Historia de la Educación Latinoamericana, 12, 62-78.

Angulo, A. (2007). Conceptos pedagógicos alemanes en la educación colombiana: La Segunda Guerra Mundial y la actualidad. Matices en Lenguas Extranjeras, 1, 1-3.

Antiseri, D. y Reale, G. (1999). El positivismo. En D. Antiseri y G. Reale (Eds.), Historia del pensamiento filosófico y cientifico (p. 274). España: Herder.

Arango, G. (1958). Primer Manifiesto Nadaísta. Medellín: Amistad.

Carrillo, C. (2006). Grupos poéticos innovadores de la década de los sesenta en Latinoamérica. Contribuciones desde Coatepec, 10, 63-87.

Foucault, M. (1968). Las palabras y las cosas: para una arqueología de las ciencias humanas. Argentina: Siglo XxI.

Gadamer, H. G. (1993). Verdad y método. Salamanca: Sígueme.

García-Perea, M. D. (1999). Hermenéutica: una posibilidad de formación. Tiempo de Educar, 1(2), 95-117.

Gutiérrez, G. (2003). Psicología experimental y psicología comparada. En L. Flórez (Ed.), El legado de Rubén Ardila. Psicología: de la biología a la cultura (pp. 82-102). Bogotá: Universidad Nacional de Colombia.

Heidegger, M. (1999). Tiempo y ser. Madrid: Tecnos.

Helg, A. (1987). La educación en Colombia 1918-1957: Una historia social, económica y política. Bogotá: Cerec.

Jiménez, J. (2008). Las ideas positivistas en la América Latina del siglo XIX. Revista via iuris, 5, 91-102.

Maturana, H. (2002). El sentido de lo humano. España: Dolmen. 
Muñoz, E. (2007). Heidegger y la pregunta por el hombre. Veritas. Revista de Filosofía y Teología, 2(16), 91-105.

Nietzsche, F. (1982). Así habló Zarathustra. Bogotá: Oveja Negra.

Nietzsche, F. (2010). La gaya ciencia. Madrid: Edaf.

Ocampo, J. (1998). Los orígenes de las universidades pedagógicas en Colombia. Revista Historia de la Educación Colombiana, 1, 183-197.

Peña, T. (1993). La psicología en Colombia: historia de una disciplina y una profesión. En I. C. Caldas (Ed.), Historia social de la ciencia en Colombia (pp. 1-62). Bogotá: Colciencias.

Rivero, P. y Rivara, G. (2002). Perspectivas nietzcheanas: reflexiones en torno al pensamiento de Nietzsche. México: UNAM.
Rodríguez-Pouget, S. (2008, agosto 28). La Furia Nadaísta. El Tiempo. Recuperado de http://www.eltiempo.com/ archivo/documento/CMS-4474740

Santiesteban, L. (2005). Heidegger: la relación de su pensar con la antropología. Signos Filosóficos, 7(13), 73-103.

Sprung, L. y Sprung, H. (1983). Gustav Theodor Fechner y el surgimiento de la psicología experimental. Revista Latinoamericana de Psicología, 15(3), 349-368.

Vattimo, G. (1994). En torno a la posmodernidad. Barcelona: Anthropos. 